\title{
A moderated cumulative model of personality adjustment in divorced adults: implications for counselling
}

\author{
Diogo Lamela (10a ${ }^{a}$, Bárbara Figueiredo $\mathbb{1}^{b}$ and Alice Bastos ${ }^{c}$ \\ aLusófona University of Porto, Porto, Portugal; ${ }^{b}$ School of Psychology, University of Minho, Braga, Portugal; ${ }^{\text {cSSchool }}$ \\ of Education, Polytechnic Institute of Viana do Castelo, Viana do Castelo, Portugal
}

\begin{abstract}
Using a life-span developmental psychology model of positive personality adjustment, this study had two aims. First, this study aimed to compare additive and threshold cumulative models of personality adjustment after divorce. The cumulative effect hypothesis states that the number of indicators is a more accurate predictor of an outcome than any single indicator considered individually. The second aim was to test whether the association between the positive personality adjustment cumulative model and satisfaction with life (selected as the subjective criterion of personality adjustment) would be moderated by divorce-related variables. Divorced adults $(N=460)$ were asked to answer to self-report measures of indicators/correlates of personality adjustment. Results supported an additive cumulative model of satisfaction with life, in which the more number of personality adjustment indicators, the more divorce-related satisfaction with life. The association between the cumulative index of personality adjustment and satisfaction with life was moderated by time since divorce and divorce initiator status. Implications for counselling are discussed.
\end{abstract}

\section{ARTICLE HISTORY}

Received 7 March 2016

Revised 26 March 2017

Accepted 18 May 2017

\section{KEYWORDS}

Personality; divorce; life satisfaction; adjustment; counselling; well-being

A sensitive issue in personality field is how to conceptualise and empirically test positive personality adjustment during adulthood. Some authors have outlined that life events seem to operate as crucial generators of developmental changes in personality system (Specht, Egloff, \& Schmukle, 2011; Sutin, Costa, Wethington, \& Eaton, 2010; Uglanova \& Staudinger, 2013). Divorce has been suggested as one of the most challenging life events in adulthood (Middeldorp, Cath, Beem, Willemsen, \& Boomsma, 2008; Miller, Chen, \& Zhou, 2007; Mol et al., 2005). Marital dissolution requires a demanding adaptation to significant changes that may concurrently occur in a variety of domains of divorced adults' life (Lamela, Figueiredo, \& Bastos, 2010). Past research has revealed that divorced adults who reported higher levels of subjective well-being are those that masterly managed with the challenging tasks triggered by divorce process (Andreß \& Bröckel, 2007; Kramrei, Coit, Martin, Fogo, \& Mahoney, 2007; Lamela \& Figueiredo, 2011; Yárnoz-Yaben \& González, 2010). However, little is known about how personality characteristics could interact between each other to predict divorce-related positive personality adjustment.

According to the positive adult personality development model (Staudinger \& Bowen, 2010; Staudinger \& Kessler, 2009; Staudinger \& Kunzmann, 2005), personality adjustment is defined by the individuals' degree of proficiency in negotiating, managing and coping with developmental challenges that synchronically may occur in biological, psychological and interpersonal lives' domains. Personality adjustment is evaluated from how developmental constrains and opportunities that arise 
from history-culture-age-graded and idiosyncratic developmental contexts are adaptively managed (Staudinger \& Bowen, 2010). Positive personality adjustment is triggered by the successful management of a developmental-contextual world in order to achieve, preserve or recover subjective wellbeing. Therefore, according to Staudinger's model, personality adjustment can be evaluated by employing subjective and objective criteria. Subjective well-being is conceptualised as the main subjective criterion of personality adjustment, while competence, everyday effective functioning and longevity are considered as the major objective criteria of personality adjustment (Staudinger \& Bowen, 2010; Staudinger \& Kunzmann, 2005).

Previous empirical research about the association between personality-based indicators and postdivorce personality adjustment has tested personality adjustment predictors in isolation. Post-divorce subjective well-being has been predicted by higher levels of self-acceptance (Sbarra, Smith, \& Mehl, 2012), self-concept clarity (Slotter, Gardner, \& Finkel, 2010), self-esteem (Waller \& MacDonald, 2010), extraversion trait (Perrig-Chiello \& Perren, 2005) and large repertoire of coping styles (Tein, Sandler, \& Zautra, 2000). Despite such studies are essential for testing and finding evidence for mapping the positive personality adjustment, just consider the individual weight of each indicator in subjective well-being may be not capture the complexity of personality adjustment. Notwithstanding the personality units used as indicators of personality adjustment are isolated constructs, personality adjustment may be more broadly understood by the cumulative interaction of those indicators. In fact, considering only how indicators operate individually prove quite inappropriate to predict positive personality adjustment (Dörner, 2006). Alternatively, it is more plausible to cogitate that subjective well-being is only expected whether the focal indicators of personality adjustment co-occur synchronically to generate a particular profile.

However, another interesting question is to understand how these indicators will perform together to predict personality adjustment. Within personality psychology, the main strategy to understand the potential interaction between personality units is by creating theory or empiricaldriven clusters of indicators in order to construct personality profiles aiming to predict certain outcomes (Helson \& Srivastava, 2001; Labouvie-Vief \& Medler, 2002). Positive personality adjustment as any other personality outcome - could be however better described by an interactive cumulative pattern of these indicators. In other scientific fields, it is well-established that an outcome is better determined by the accumulation of indicators/predictors, independently of the presence or absence of specific outcome-related indicators. The cumulative effect hypothesis states that the number of indicators is a more efficient and accurate predictor of a dependent variable than any single indicator considered individually (Rutter, 1981). This approach considers the fact that a predictor variable rarely occurs in isolation but in general co-vary with other predictors.

Two cumulative effect models may be expected. The cumulative effect may operate in a threshold fashion, in which the odds of an outcome occurrence increases dramatically in presence of a certain number of indicators (Appleyard, Egeland, Dulmen, \& Alan Sroufe, 2005; Rutter, 1981). This quadratic trend model hypothesised that, beyond a certain number, the combined effect of the interactive accumulation of concurrent indicators is more strikingly predictive of the outcome variable than the summation of their separate effects (Appleyard et al., 2005; Jones, Forehand, Brody, \& Armistead, 2002). Conversely, the additive cumulative effect model asserts a progressive linear effect of indicators, with no multiplicative effect of the indicators on each other, whereby the greater the number of predictors, the greater the prevalence of the outcome variable (Everhart, Fiese, \& Smyth, 2008; Sameroff, Seifer, Baldwin, \& Baldwin, 1993). Therefore, it is plausible to hypothesise that the more indicators of personality adjustment presented by divorced adults, the more subjective well-being they will report, regardless of which indicators contribute individually to personality adjustment.

The cumulative models offer an estimation of how indicators fall together to underlie patterns of personality adjustment. Nevertheless, this cumulative analytic approach allows only to examine associations between the cumulative interaction of indicators and the outcomes. A more comprehensive portrait of these associations would still be possible whether the effect of moderating variables 
was considered as well. Among the variables empirically tested in the literature, divorce initiator status and time since divorce are highlighted as two of the most significant moderators of postdivorce outcomes (Wallerstein, 1986). Non-initiators of the relationship dissolution perceived the end of the relationship as more stressful and exhibited more psychological distress, more feelings of shock with the break-up, inferior sense of event controllability and predictability and more emotional attachment to the ex-partner (Buehler, 1987; Davis, Shaver, \& Vernon, 2003; Frazier \& Cook, 1993; Sakraida, 2005; Wang \& Amato, 2000). These negative outcomes appeared to be similar between non-initiators and mutually initiators of the intimate relationship dissolution (Davis et al., 2003). On the other hand, when compared with their recently divorced counterparts, non-recently divorced adults reported more subjective well-being, fewer psychological distress, higher adjustment to the developmental tasks triggered by divorce, higher levels of ego development and personal growth (Buehler, 1987; Bursik, 1991; Hetherington \& Kelly, 2002; Lamela, Figueiredo, Bastos, \& Martins, 2014; Lucas, 2005).

\section{The present study}

In the current research, a cross-sectional study was conducted to achieve two aims. Based on the Staudinger's conceptual framework, the first aim was to compare additive and threshold cumulative models of personality adjustment. Life satisfaction was selected as subjective criterion of personality adjustment, since previous research has systematically studied this cognitive component of subjective well-being as the main outcome of psychological adjustment to a life event. We expect that adjustment indicators will operate additively in the prediction of life satisfaction.

The second aim was to test whether the association between positive personality adjustment cumulative model and life satisfaction would be moderated by divorce features. Based on previous findings that demonstrated divorce-related variables, such as time since divorce and divorce initiation status, were linked with positive personality outcomes (Lamela et al., 2014), we examined the hypothesis that time since divorce and initiation of divorce would moderate the association between cumulative personality adjustment and life satisfaction. We expect that cumulative personality adjustment will be more robustly associated to life satisfaction among divorce initiators and nonrecently divorced adults. Based on prior research, we hypothesised that take the initiative to divorce would increase the sense of predictability and would provide more time to planning post-divorce life and, therefore, could facilitate the process of emotional detachment. Additionally, according to some authors of the Family Psychology tradition (Ahrons \& Rodgers, 1987; Hetherington \& Kelly, 2002), divorce is a process transition, in which adults have to accomplish some developmental tasks that were precipitated by marital dissolution, such as proceed to emotional and psychological detachment to the ex-spouse and develop an independent identity, guarantee their financial autonomy, reorganise their social networks, and, for divorced parents, create a cooperative coparenting relationship with the ex-spouse (Clarke-Stewart \& Brentano, 2006). Therefore, considering divorce as a demanding developmental process that requires time to manage with divorce-adjustment tasks to achieve life satisfaction, it would be more likely that non-recently divorced adults had already cope with such tasks than recently divorced individuals.

\section{Method}

\section{Participants}

The sample consisted of 460 divorced adults who participated in the Portuguese National Study about Divorce Experience. Participants included 330 women (72\%) and 130 men (28\%). All participants had Portuguese nationality and were living in Portugal. Divorced adults' ages ranged from 24 to 65 years $(M=41.7, S D=8.1)$. Participants had an average of 17 years of education $(S D=4.16$, range $6-25$ ). Most of the divorced adults were employed (85.2\%). Average income was $€ 1.827$ (SD 
$=€ 2589)$. Length of previous marriage ranged from 1 to 40 years $(M=11.08, S D=7.77$, mode $=5$ years, median $=10$ years). On average, divorce occurred at 5.19 years ( $S D=5.01$ years, range $=2$ months to 28 years, mode $=2$ months, median $=3.4$ years). Divorce was by mutual consent to $91 \%$ of participants. In $57 \%$ of the cases, divorce was initiated by the participants, in $21 \%$ by the participants' ex-spouses and in $22 \%$ by mutual decision. Twenty-six percent of the participants did not have children with ex-spouse, $40 \%$ had one child, $30 \%$ had two children and $4 \%$ had three children. One hundred and thirty participants (28\%) had a new intimate relationship and $86(19 \%)$ received psychological or psychiatric treatment in consequence of divorce.

\section{Procedures}

For the purpose of data collection, an online survey was conducted. The online survey was available on a Portuguese internet research portal for divorce research from June to October 2010. The instructions of all self-report measures were slightly modified to explicitly specify that participants should consider divorce as reference event for rating their degree of accordance with each item. Participants were recruited through electronic outreach (emails to institutional universities web accounts, and notices on national web forums, e.g. a forum of support group to divorced adults and also a forum of family issues) and announcements in the media (newspapers, radio and newspapers websites). No compensation was offered to participants. To guarantee data quality, standard methodological and ethical guidelines for Internet-based research were followed (Kraut et al., 2004; Reips, 2002), such as implementing informed consent procedures recommend by Kraut et al. (2004), using an adequate and parsimonious plan of participants' recruitment and guarding against potentially biases sample. Previous research has consistently demonstrated that Internet-based research produces trustful and reliable data equivalent to those obtained from traditional methods (Gosling, Vazire, Srivastava, \& John, 2004).

\section{Measures}

\section{Independent variables}

Indicators of personality adjustment. Adjustment dimensions of the psychological well-being. The Autonomy, Positive relations, Environment mastery and Self-acceptance scales of the Psychological Well-being Scales (PWBS; Ryff \& Keyes, 1995) were also administered. Autonomy refers to self-perception of self-regulation, self-determining and psychological independence. The Positive relations scale assesses the degree of personal capability of empathy, affection and intimacy as well as the degree that individual can develop warmth, satisfactory and trustful relationships with others. Environment mastery is defined as the personal sense of mastery and competence in managing the environment as well as the capacity of creating contexts appropriate to personal needs and values. Self-acceptance scale examines the positive attitude toward the self, the positive feelings about past life as well as the self-knowledge and acceptance of the multiple aspects of self. Each scale was comprised by seven items. Higher scores reflect best performances. The Portuguese version of the PWBS showed good psychometric properties (Novo, Duarte-Silva, \& Peralta, 1997). In the current study, Cronbach's alpha was .78 in the Autonomy scale, .72 in the Positive relations scale, .70 in the Environment mastery and .83 in the Self-acceptance scale.

Divorce-related negative affect balance. The Negativity-loneliness subscale of the Psychological Adjustment to Separation Test (PAST; Sweeper \& Halford, 2006) was used to assess negative affect balance related with the divorce process and the ex-spouse (e.g. 'I find it difficult to enjoy myself' and 'I feel desperately lonely'). This 10-item subscale is answered in a 5-point-Likert scale (1, strongly disagree to 5, strongly agree), in which higher scores reflect more negative affect. The Portuguese version of the PAST showed good psychometric properties (Lamela, Figueiredo, \& Bastos, 2014). For current sample, Cronbach's alpha was .91. 
Emotional attachment to ex-spouse. The degree of emotional attachment to ex-spouse was measured with the Attachment to ex-partner subscale of the PAST (Sweeper \& Halford, 2006). This 7-item subscale assessed the ongoing desire for emotional closeness with ex-spouse after intimate dissolution in a 5-point-Likert scale (1, strongly disagree to 5, strongly agree). Higher scores represent more sense of connectedness to ex-spouse. A Cronbach's alpha of .90 was found in this sample.

Motivation for adjustment goals. The Emotive growth motivation scale of the Portuguese version of the Growth Motivation Index (GMl; Bauer, Park, Montoya, \& Wayment, 2015) was used to assess individuals' orientation to select goals that promote a deeper experience individuals' psychosocial life, however without efforts for a deeper conceptual view of the one's experience. This scale also examines the importance of being involved in meaningful activities and relationships in a 7-point-Likert scale. Higher scores revealed higher motivation for emotive growth (i.e. motivation for personality adjustment goals). The preliminary Portuguese version of the GMI showed adequate psychometric properties (Lamela, 2013). A Cronbach's alpha of .78 was found for the current sample.

Creating cumulative index. The cumulative personality adjustment index (CAI) was generated from the personality adjustment indicators proposed by Staudinger and colleagues. To construct the CAl, seven indicators were used: (1) autonomy, (2) positive relations with others, (3) environment mastery, (4) self-acceptance, (5) divorce-related negative affect balance, (6) experience of emotional attachment to ex-spouse and (7) motivation for adjustment goals. To compute the CAl, each of the indicators was firstly transformed into a dichotomous variable. The 75 th percentile was used as cut-off criterion to dichotomise all continuous indicators, using the recommendations followed by previous studies (Gerard \& Buehler, 2004). For each indicator, participants scoring above the 75th percentile were coded as 1 to designate the presence of that personality adjustment, whereas scores under 75th percentile were coded as 0 to indicate the absence or low presence of the indicator. In consequence of higher scores in negative affect and emotional attachment to ex-spouse variables represent more negative outcomes, the 25 th percentile was employed for dichotomise these two variables instead. CAI was then tabulated by summing the dichotomised indicators of personality adjustment, respectively. CAI was treated as a continuous variable in all statistical analyses.

\section{Dependent variable}

\section{Life satisfaction}

Adults were asked to complete the 5-item Satisfaction with Life Scale (SWLS; Diener, Emmons, Larsen, \& Griffin, 1985) in order to measure the individual's internal, subjective assessment of their overall quality of life. Life satisfaction is conceptualised as the cognitive component of the subjective well-being (Diener, Oishi, \& Lucas, 2009). Higher scores represent higher levels of life satisfaction. The Portuguese version of the SWLS showed excellent values of validity and reliability (Neto, 1993). For the current data set, Cronbach's alpha was .87.

\section{Results}

\section{Aim 1: Cumulative models of personality adjustment}

Our next set of analyses examined whether life satisfaction was better predicted by CAI as a linear (additive model) or as quadratic (threshold model) functions. A hierarchical regression model to predict life satisfaction was conducted. The predictor variables were firstly standardised (z-scores) to reduce potential multicollinearity (Afifi, Clark, \& May, 2011). In model 1, in order to predict life satisfaction, CAl as a linear term was entered in Step 1 and CAI as a quadratic term $\left(\mathrm{CAI}^{2}=\mathrm{CAI} \times \mathrm{CAI}\right)$ in 
Step 2. Finally, a two-way ANOVA followed by Scheffé post hoc tests were performed to confirm the linear or quadratic nature of CAI in predicting life satisfaction.

\section{Cumulative model of personality adjustment}

Preliminary analyses. A correlation matrix of individual continuous personality adjustment indicators, CAl and life satisfaction (dependent variable) is presented in Table 1 . Since only $4.7 \%$ of the participants met criteria for the presence of more than five personality adjustment indicators, levels of ' 6 ' or ' 7 ' were transformed to ' 5 ' for the cumulative index. Thirty-three percent of the participants $(n=154)$ did not present any indicator of personality adjustment (75th percentile cut-off), while $20 \%(n=92)$ presented one indicator, $15 \%(n=70)$ two indicators, $11 \%(n=48)$ three indicators, $10 \%$ $(n=46)$ four indicators and $11 \%(n=50)$ between five and seven indicators. Participants' mean for CAI total score was $1.76(S D=1.72)$. Preliminary analyses were conducted to examine relations between CAl and the proposed moderator variables. CAl differed by time since divorce, $t(458)=-4.51, p$ $<.001$, Cohen's $d=0.45$, with recently divorced participants revealing significantly less cumulative personality adjustment $(M=1.29, S D=1.43)$ than non-recently divorced $(M=2.03, S D=1.82)$. No differences on CAI between divorce non-initiators and initiators were found, $t(458)=-0.73, p$ $>.05$, Cohen's $d=0.07$.

Additive versus threshold cumulative model of personality adjustment. The cumulative model of personality adjustment predicted significantly participants' life satisfaction as a linear function, $F(1$, $459)=236.93, p<.001)$. The addition of the quadratic term to the hierarchical regression model did not contribute to a significant improvement in fit over the linear function, $\Delta F(2,458)=3.34, p>.05$. The quadratic function did not explain additional variance in participants' CAl scores beyond that accounted by the linear function $(\beta=-.09, p>.05)$. Moreover, the effect size attributable to the addition of the quadratic function in the hierarchical regression model was very small $\left(\Delta f^{2}=\right.$ 0.007). Participants' life satisfaction increased as the presence of cumulative personality adjustment indicators additively increased as well (Table 2 and Figure 1). Subsequent analysis of variance confirmed the linear nature of cumulative personality adjustment on life satisfaction, $F(5,455)=49.54$, $p<.001$. Post hoc Scheffé tests revealed that life satisfaction differed significantly between all groups (all $p<.01$ ), showing that participants with five or more indicators of cumulative personality adjustment had the highest life satisfaction $(M=29.72, S D=3.78)$, followed by divorced adults with four indicators $(M=27.47, S D=2.79)$, by the participants with three indicators $(M=25.33, S D=4.90)$, by those with two indicators $(M=24.82, S D=5.76)$, by divorced adults with one indicator $(M=$ $20.34, S D=6.68)$ and by the participants with no indicators of personality adjustment $(M=17.87$, $S D=6.56)$.

Table 1. Descriptive statistics and bivariate correlations of continuous personality adjustment indicators, CAI and dependent variables.

\begin{tabular}{|c|c|c|c|c|c|c|c|c|c|c|}
\hline Variable & $M$ & $S D$ & 1. & 2. & 3. & 4. & 5. & 6. & 7. & 8. \\
\hline \multicolumn{11}{|c|}{ Cumulative model of personality adjustment } \\
\hline 1. Autonomy & 33.61 & 5.65 & & & & & & & & \\
\hline 2. Positive relations & 31.76 & 5.42 & $.37^{* *}$ & & & & & & & \\
\hline 3. Environment mastery & 30.20 & 5.60 & $.42^{* *}$ & $.59^{* *}$ & & & & & & \\
\hline 4. Self-acceptance & 31.48 & 7.24 & $.55^{* *}$ & $.64^{* *}$ & $.72^{* *}$ & & & & & \\
\hline $\begin{array}{l}\text { 5. Divorce-related negative } \\
\text { affect }\end{array}$ & 22.03 & 9.72 & $-.41^{* *}$ & $-.44^{* *}$ & $-.54^{* *}$ & $-65^{* *}$ & & & & \\
\hline $\begin{array}{l}\text { 6. Emotional attachment to ex- } \\
\text { spouse }\end{array}$ & 13.50 & 7.02 & $-.34^{* *}$ & $-.16^{* *}$ & $-.28^{* *}$ & $-.39 * *$ & $.70^{* *}$ & & & \\
\hline $\begin{array}{l}\text { 7. Motivation for adjustment } \\
\text { goals }\end{array}$ & 43.37 & 7.68 & $.20^{* *}$ & $.20^{* *}$ & $.20^{* *}$ & $.35^{* *}$ & $-19^{* *}$ & $-.19^{* *}$ & & \\
\hline 8. CAI & 1.76 & 1.72 & $.56^{* *}$ & $.63^{* *}$ & $.67^{* *}$ & $.71^{* *}$ & $-.60^{* *}$ & $-.47^{* *}$ & $.40^{* *}$ & \\
\hline 9. Satisfaction with life & 22.45 & 7.13 & $.34^{* *}$ & $.51^{* *}$ & $.63^{* *}$ & $.75^{* *}$ & $-.61^{* *}$ & $-.33^{* *}$ & $.33^{* *}$ & $.58^{* *}$ \\
\hline
\end{tabular}

Note: CAl: cumulative adjustment index.

${ }^{* *} p<.001$. 
Table 2. Hierarchical multiple regressions results for CAI as a linear term, and CAI as a quadratic term.

\begin{tabular}{|c|c|c|c|c|c|c|}
\hline Variable & $B(S E)$ & B 95\% Cl & $\beta$ & $R^{2}$ & $\Delta R^{2}$ & $f^{2}$ \\
\hline \multicolumn{7}{|c|}{ Outcome: satisfaction with life } \\
\hline \multicolumn{7}{|c|}{ Step 1} \\
\hline CAI & $4.17(0.27)$ & {$[3.63,4,69]$} & $.58^{*}$ & & & \\
\hline$F(1,459)$ & $236.93^{*}$ & & & .341 & & 0.52 \\
\hline \multicolumn{7}{|l|}{ Step 2} \\
\hline $\mathrm{CAl} \times \mathrm{CAl}$ & $-0.60(0.33)$ & {$[-1.24,0.05]$} & -.09 & & & \\
\hline$F(2,458)$ change & 3.34 & & & .346 & .005 & 0.53 \\
\hline
\end{tabular}

Notes: CAl: cumulative adjustment index; $95 \%$ Cl: confidence interval; $f^{2}$ : Cohen's effect size for multiple regression. ${ }^{*} p<.001$.

\section{Aim 2: The moderating effect of time since divorce and divorce initiator status on CAl and life satisfaction}

A hierarchical regression model was conducted to test the moderating role of time since divorce and divorce initiator status on the association between CAI and life satisfaction. In this model, Step 1 included the main effects (i.e. CAl, time since divorce, divorce initiator status), Step 2 added three two-way interactions (CAI by time since divorce, CAl by divorce initiator status and time since divorce by divorce initiator status) and Step 3 examined a three-way interaction (CAl by time since divorce by divorce initiator status). Prior to generating the interaction terms, all variables were standardised, with exception of the dichotomous variable 'divorce initiator status' $(0=$ divorce noninitiators/mutual consent and $1=$ divorce initiators).

The final significant step in the model accounted for $39 \%$ of the variance in life satisfaction. Step 1 revealed main effects for time since divorce on life satisfaction $(\beta=.11, p<.001)$. At Step 2 , the twoway interaction terms were entered in order to test the moderating role of time since divorce and divorce initiator status on the association between CAI and life satisfaction. In spite of the addition of this product term increased the explained variance in life satisfaction $\left(\Delta R^{2}=.028, p<.001, f^{2}=\right.$ 0.63), none of the two-way interaction formed by CAl emerged as significant (Table 3 ).

In the third step, the three-way interaction term was entered to test second-order moderation. The explained variance in life satisfaction significantly increased by the addition of Step $3\left(\Delta R^{2}=.006, p\right.$ $<.05, f^{2}=0.65$ ), suggesting that $\mathrm{CAl}$, time since divorce and divorce initiator status entered in Step 3 ,

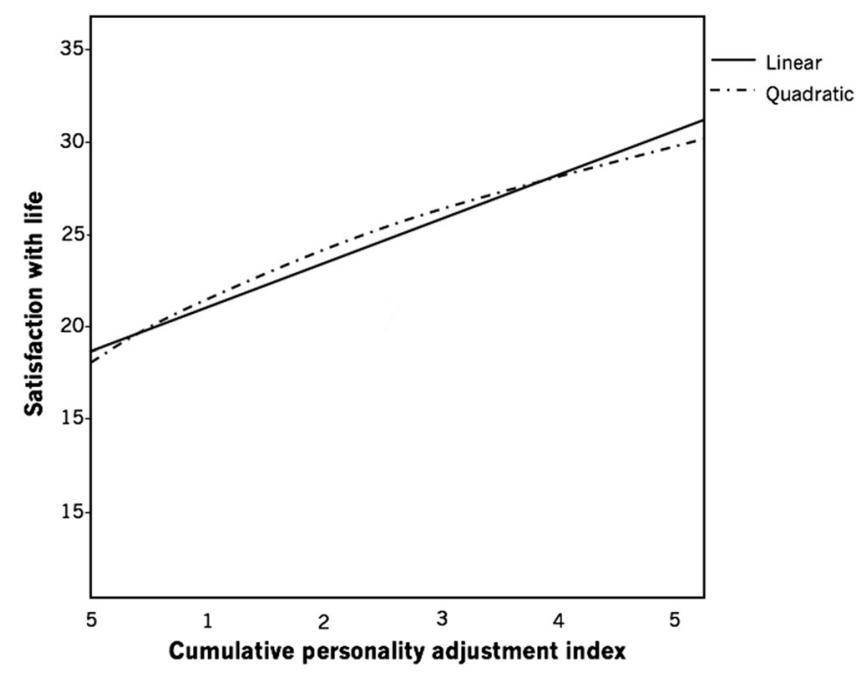

Figure 1. Mean of outcomes variables for each level of the cumulative indexes. The figure displays mean of satisfaction for each level of the cumulative personality adjustment index (CAI). 
Table 3. Hierarchical regression predicting life satisfaction from CAl, time since divorce and divorce initiator status.

\begin{tabular}{|c|c|c|c|c|c|c|}
\hline Variable & $B(S E)$ & B 95\% Cl & $\beta$ & $R^{2}$ & $\Delta R^{2}$ & $f^{2}$ \\
\hline \multicolumn{7}{|l|}{ Step 1} \\
\hline CAI & $0.57(0.04)$ & {$[0.49,0.64]$} & $.57^{* *}$ & & & \\
\hline Time since divorce & $0.11(0.04)$ & {$[0.04,0.19]$} & $.11^{* *}$ & & & \\
\hline Divorce initiator status & $0.13(0.08)$ & {$[-0.02,0.28]$} & .06 & & & \\
\hline$F(3,457)$ & & $84.89^{* *}$ & & $.358^{* *}$ & & 0.56 \\
\hline \multicolumn{7}{|l|}{ Step 2} \\
\hline CAl $\times$ Time since divorce & $-0.04(.04)$ & {$[-0.12,0.04]$} & -.04 & & & \\
\hline CAI $\times$ Divorce initiator status & $-0.14(0.08)$ & {$[-0.29,0.01]$} & -.11 & & & \\
\hline Time since divorce $\times$ Divorce initiator status & $0.31(0.08)$ & {$[0.17,0.50)$} & $.23^{* *}$ & & & \\
\hline$F(6,454)$ change & & $6.95^{* *}$ & & $.387^{* *}$ & .028 & 0.63 \\
\hline \multicolumn{7}{|l|}{ Step 3} \\
\hline CAI $\times$ Time since divorce $\times$ Divorce initiator status & $-0.17(0.08)$ & {$[-0.33,-0.01]$} & $-.12^{*}$ & & & \\
\hline$F(7,453)$ change & & $4.45^{*}$ & & $.393^{*}$ & .006 & 0.65 \\
\hline
\end{tabular}

Notes: CAl: cumulative adjustment index; divorce initiator status: $0=$ divorce non-initiators/mutual consent and $1=$ divorce initiators.

${ }^{*} p<.05$.

${ }^{* *} p<.001$.

significantly account for differences in life satisfaction among the divorced adults $(\beta=.12, p<.05)$. In order to interpret these results, the interaction effects were for plotted for the two levels of divorce initiator status (divorce non-initiators and divorce initiators). For each level of divorce initiator status, the association between CAI and life satisfaction for low and high time since divorce was plotted. Low time since divorce was defined as minus one standard deviation from the mean and high time since divorce as plus one standard deviation from the mean (Aiken \& West, 1991; Cohen, Cohen, West, \& Aiken, 2003). Simple slopes analyses were conducted as recommended by Aiken and West (1991). Slope difference tests were also computed to probe the three-way interaction effect by examining whether differences between pairs of slopes were significantly different from zero (Dawson \& Richter, 2006). The results are shown in Figure 2.

In the divorce initiators group (Figure 2, panel B), despite associations between CAI and life satisfaction were significant at both high $(B=.41, t=3.54, p<.001)$ and low $(B=.64, t=4.87, p>.001)$ levels of time since divorce, the slope difference tests revealed that this association was significantly stronger among divorce initiators with high time since divorce $(t=-2.19, p<.05)$. Among divorce non-initiators individuals (Figure 2, panel $A$ ), CAl was related to life satisfaction when time since divorce was high $(B=.72, t=7.15, p<.001)$ and when was low $(B=.60, t=6.01, p>.001)$. However,
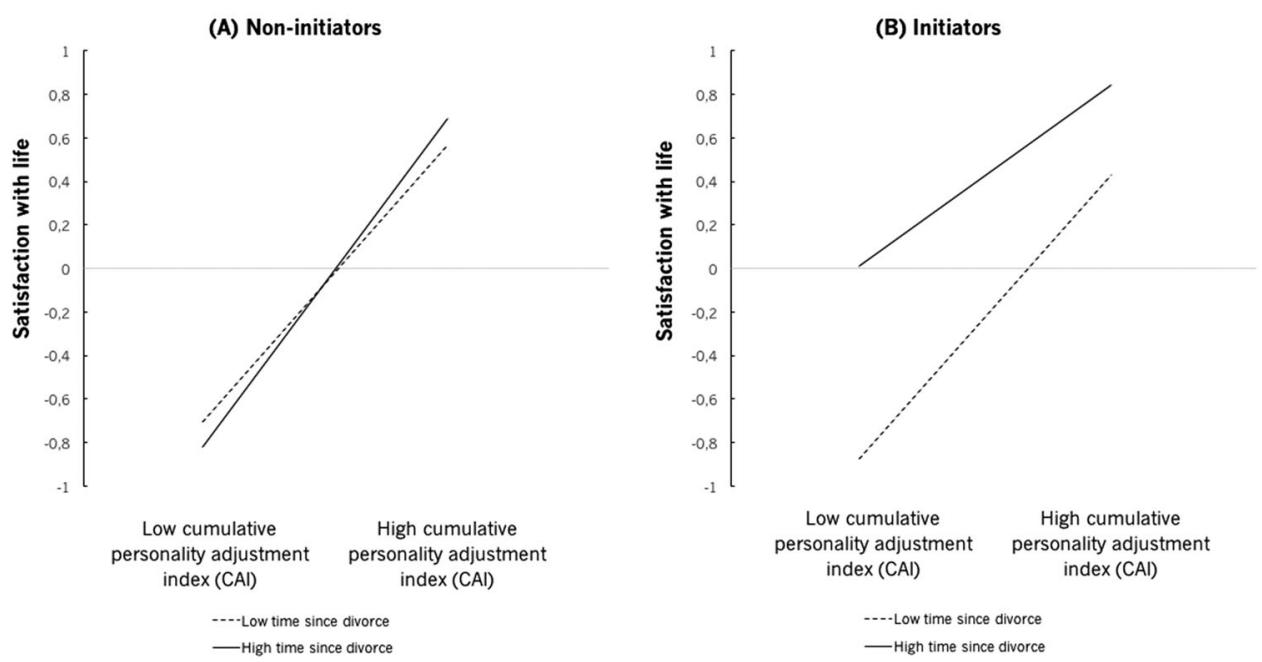

Figure 2. Interaction between CAl, divorce initiator status and time since divorce in predicting satisfaction with life. 
these two slopes failed to differ from each other $(t=-1.71, p>.05)$. Additionally, among the participants with high time since divorce, simple slopes analysis revealed that the association between CAI and life satisfaction was significantly stronger for divorce initiators than divorce non-initiators ( $t=$ $-2.71, p<.001)$.

\section{Discussion}

In the current research, we pursued two major aims. First, we wanted to test whether life satisfaction and personal would be predicted by cumulative indexes constructed based on theory-driven positive personality indicators. Second, we examined the moderating role of time since divorce and divorce initiator status on the association between CAI and life satisfaction and CGI and personal growth.

The accumulation of indicators of positive personality adjustment explained a moderate to large amount of variance of life satisfaction. Our results supported an additive cumulative model, in which the gradual accumulation of indicators differentiated individuals' life satisfaction. These results suggest that while adults who report more indicators of personality adjustment had an increased likelihood to experience life satisfaction, there is no evidence for a specific threshold beyond which their life satisfaction turn dramatically and multiplicatively improved. These findings are in line with longitudinal studies that reported a linear and progressive increase of life satisfaction after divorce for the majority of the individuals (Lucas, 2005; Luhmann, Hofmann, Eid, \& Lucas, 2012; Mancini, Bonanno, \& Clark, 2011). Thus, this linear trend suggests that life satisfaction after divorce is a continuous and gradual process of cognitive and emotional adjustment and it may be intrinsically dependent of the successful resolution of developmental tasks triggered by divorce. In line with previous research (Hewitt \& Turrell, 2011), the three-way moderation (CAI $\times$ divorce initiator status $\times$ time since divorce) found as significant suggests that the association between CAI and life satisfaction is complexly moderated. More concretely, CAI was more strongly related to life satisfaction among individuals with high time since divorce and this association was even stronger for those who initiated their divorce. By contrast with our hypotheses, no other moderation effect was found in the association between CAI and life satisfaction.

Additionally, as Staudinger and colleagues suggested, the individuals' ability to masterly cope with contextual demands has a functional value to positive functioning of the individual and the community. A successful communal life is strictly dependent of incidence rate of personal adjustment (see Staudinger \& Bowen, 2010 to deeper discussion about the mechanisms through which societies promote personal adjustment). Consequently, as individual adjustment is a main evolutionary demand for communal functioning, societies make effort to assurance that all their members have access to indispensable resources to encounter the society's demands and expectations. In the last decades, at least in the majority of the Western countries, societies have developed some social resources that promote adults' adjustment to divorce, such as divorce acts in which the legal figure of litigious divorce is abolished, the existence of family mediation services, the access to public services of psychotherapy, the positive discrimination of divorced adults with children in taxes and the additional social security supports to single parents. Therefore, societies stimulate and provide tools to adults adjust gradually to this transition with high degrees of success.

\section{Limitations and future research}

The results of this research should, however, be interpreted bearing some limitations in mind. First, the dichotomisation of the indicators of personality adjustment was computed using a cut-off criterion based on the sample mean. Therefore, the cumulative index score are sample-specific and special caution is generalisation of the results is recommended. Second, we used the 75th percentile (or 25th percentile in two variables) as standardised cut-off criterion for dichotomisation, assuming theoretically that high scores were more indicative of high/ideal performance for all variables. However, for some variables, higher scores may not consensually represent the best indicator of 
personality adjustment. For example, while some studies demonstrated that a high level of selfacceptance is a major protective factor for positive mental health and beneficial for higher levels of life satisfaction, others studies however revealed that high self-acceptance may lead to an unrealistic overestimation of individuals' sense of competence twisting their performance and, by this way, reduce their ability to adjust (Baumeister, Campbell, Krueger, \& Vohs, 2003; Orth, Robins, \& Widaman, 2012; Sowislo \& Orth, 2013). Therefore, we opted to employ a uniform cut-off criterion for all variables. Third, the sample was globally composed by highly educated participants that could have reduced the variance in the associations between the criteria of positive personality adjustment and the cumulative indexes. Fourth, we did not control whether divorce was considered as a turning-point event to the participants. Despite participants were clearly instructed to answer to self-report instruments having in mind their divorce as reference point, the present results could be even more vigorous whether control groups were used (e.g. a control group composed by adults with no major life events and a control group composed with adults with more or other major life events). Finally, fifth, we only measured a subjective criterion of positive personality adjustment. Future research should employ measures of objective criteria of positive personality, such as behavioural, physical and neurocognitive assessment of personal functioning as objective criteria of personality adjustment.

Globally, our findings demonstrated that single indicators of personality adjustment exert significant effects on life satisfaction. However, it was evident that most divorced adults with no or one or two indicators of positive personality adjustment did not report the major levels of life satisfaction. The cumulative effect found in our study underlies the assumption that personality is a composite self-system that should be assessed using an interaction perspective of the personality units. In fact, these results provide some empirical evidence of Staudinger's model of positive personality development and also they suggest that divorce has a positive challenging impact on personality adjustment during adulthood.

\section{Implications for counselling}

An identified conceptual caveat of previous research in the divorce field is the adoption of a pathological view of this life event (Hetherington \& Kelly, 2002). In particular, some scholars have suggested that research is mainly focussed on deficits, developmental loses, and personality traits associated with higher odds of divorce and chronical adjustment problems after this family transition (Ahrons \& Rodgers, 1987; Masheter, 1998). With few exceptions (e.g. Lamela, Castro, \& Figueiredo, 2010), this deficit culture in research is being translated to counselling and clinical interventions. For example, a recent meta-analysis revealed that the majority of counselling and psychotherapeutic programmes for divorced adults is designed to mainly alleviate psychopathology symptoms and/or psychological distress associated with divorce process, with limited clinical emphasis in positive psychological processes (Strouse \& Roehrle, 2011). In contrast with this framework, a small body of theoretical work has suggesting that divorce should be conceptualised as a challenging life event that might promote or jeopardise individuals' developmental adaptation (e.g. Hetherington \& Kelly, 2002). Under this perspective, our study sought to examine the associations between the cooccurrence of indicators personality adjustment and life satisfaction in divorced adults. Having in mind the developmental nature of divorce transition, three major implications for counselling may be drawn from our findings.

Firstly, by showing that divorced people may experience differential levels of life satisfaction, our results suggest that counsellors should not only assess psychopathological symptoms and signals of psychosocial distress, but also routinely include measures of subjective well-being in their assessment protocols. As life satisfaction was associated with the accumulation of personality indicators of psychological adjustment, our findings also suggest that clinical assessment may benefit from the inclusion of cognitive, emotional and behavioural measures of personality, rather than a unidimensional approach of assessment of this construct. Multidimensional assessment procedures may be required for the translation of our findings into more effective counselling practices with adults in divorce transition. 
Secondly, the study findings suggest that counselling with divorced adults should be geared toward stimulating individual's reserve capacity. Based on life-span developmental psychology principles, a plausible thesis to our results is that the perceived gains in life satisfaction after divorce might be associated with individuals' efforts to amplify personality mechanisms that enhance their reserve capacity to cope with divorce-related developmental challenges. Reserve capacity is defined as individuals' potential for change and for growth and how flexible and vigorous they might be in managing developmental challenges and opportunities (Staudinger, Marsiske, \& Baltes, 1995). Individuals' reserve capacity is constituted by internal (e.g. personality features, cognitive abilities and physical health) and external resources (e.g. education and social networks) that could be potentially activated to negotiate those developmental demands (Staudinger \& Bowen, 2010). As resources of reserve capacity, personality features may operate as a key psychological tool not only to repair and manage potential developmental loses associated with end of marriage but also to promote selfinitiatives of developmental gains in psychological adjustment after this life event. Therefore, divorced adults in counselling may benefit from strategies that activate latent personality resources in order to stimulate their functional plasticity. The efficacy of counselling and therapeutic interventions for expanding personality resources has been documented in previous seminal work (Fave, 2016; Mühlig-Versen, Bowen, \& Staudinger, 2012; Weiss, Westerhof, Bohlmeijer, \& Coyne, 2016). In particular, one counselling/therapy approach that may hold promise in this area is the well-being therapy (Fave, 2016). Conceptually grounded in Ryff's model of psychological well-being (Ryff \& Keyes, 1995), this validated approach was designed to improve subjective well-being, through several therapeutic strategies, including self-observation, use of a structured diary, cognitive techniques and homework. As the main therapeutic target of this approach is the expansion of some of the indicators of personality adjustment addressed in the current research, it may be a valuable clinical tool to apply our findings in counselling settings.

Finally, our results also highlight the potential benefit of targeting divorce developmental tasks as a key therapeutic element in counselling with divorced adults. Developmental models of divorce have suggested that the primary goal of adults during divorce transition is to respond as masterly as they can to contextual changes operated in their environment (Hetherington \& Kelly, 2002). As a result, adults invest available resources in their personal adjustment and, for those who are parents, in their children's psychological adjustment as well. Since subjective well-being reacts to life changes, it is plausible to think that higher subjective well-being may be associated with a more successful allocation of personal resources in the resolution of divorce-related developmental demands. The addictive relationship between cumulative indicators of personality adjustment and life satisfaction found in our study may, thus, reflect a positive and successful resolution of the developmental tasks triggered by divorce. In line with this hypothesis, counselling should focus on specific developmental tasks associated with higher levels of affective self-regulation, psychosocial adjustment and subjective well-being (Clarke-Stewart \& Brentano, 2006; Hetherington \& Kelly, 2002; Lamela et al., 2010). In particular, counselling should foster the management of emotional distress caused by the grieving process for the loss of the marriage, the achievement of emotional and psychological detachment to the ex-spouse, the accommodation of possible changes in identity, the promotion of self-actualisation initiatives triggered by divorce and the reorganisation of social networks. For divorced parents, counselling could also promote opportunities for the formation of a cooperative coparenting relationship with the ex-spouse and the reorganisation of clients' parenting practices and their relationship with children (Lamela, Figueiredo, Bastos, \& Feinberg, 2016). Therapeutic strategies addressed in developmental counseling protocols might be particularly effective to augment adults' skills to masterly manage the challenges and opportunities elicited by divorce-specific developmental tasks (Ivey, Ivey, Myers, \& Sweeney, 2005).

Taken together, our findings may suggest that life satisfaction may be formulated not only as a higher-order counselling goal but also as a criterion of counselling effectiveness. Identifying the occurrence of positive outcomes offers a more comprehensive portrait of clients' overall functioning during this transition, and thereby, a more complete analysis of counselling effectiveness. More 
specifically, as higher levels of subjective well-being may reflect a successful activation of internal and external resources (i.e. reserve capacity) to positively solve divorce-specific developmental tasks, measures of life satisfaction may be used to evaluate counselling effectiveness with adults who seek help during this challenging developmental transition.

\section{Disclosure statement}

No potential conflict of interest was reported by the authors.

\section{Funding}

This research was supported by the Portuguese Foundation of Science and Technology (Fundação para a Ciência e Tecnologia) through a fellowship to the first author (SFRH/BD/43525/2008).

\section{Notes on contributors}

Diogo Lamela is Assistant Professor of Clinical Psychology at the Lusófona University of Porto, Portugal.

Bárbara Figueiredo is Professor of Clinical Psychology at the University of Minho, Portugal.

Alice Bastos is Associate Professor of Developmental Psychology and Gerontology at the Polytechnic Institute of Viana do Castelo, Portugal.

\section{ORCID}

Diogo Lamela (iD http://orcid.org/0000-0002-9466-0717

Bárbara Figueiredo (D) http://orcid.org/0000-0002-8209-7445

\section{References}

Afifi, A., Clark, V., \& May, S. (2011). Practical multivariate analysis (5th ed.). Boca Raton, FL: CRC Press.

Ahrons, C., \& Rodgers, R. (1987). Divorced families: A multidisciplinary developmental view. New York, NY: Norton.

Aiken, L., \& West, S. (1991). Multiple regression?: Testing and interpreting interactions. Newbury Park, CA: Sage Publications.

Andreß, H., \& Bröckel, M. (2007). Income and life satisfaction after marital disruption in Germany. Journal of Marriage and Family, 69, 500-512. doi:10.1111/j.1741-3737.2007.00379.x

Appleyard, K., Egeland, B., Dulmen, M., \& Alan Sroufe, L. (2005). When more is not better: The role of cumulative risk in child behavior outcomes. Journal of Child Psychology and Psychiatry, 46, 235-245. doi:10.1111/j.1469-7610.2004.00351.x

Bauer, J., Park, S., Montoya, R., \& Wayment, H. (2015). Growth motivation toward two paths of eudaimonic self-development. Journal of Happiness Studies, 16, 185-210. doi:10.1007/s10902-014-9504-9

Baumeister, R., Campbell, J., Krueger, J., \& Vohs, K. (2003). Does high self-esteem cause better performance, interpersonal success, happiness, or healthier lifestyles? Psychological Science in the Public Interest, 4, 1-44. doi:10.1111/1529-1006.01431

Buehler, C. (1987). Initiator status and the divorce transition. Family Relations, 36, 82-86. doi:10.2307/584653

Bursik, K. (1991). Adaptation to divorce and ego development in adult women. Journal of Personality and Social Psychology, 60, 300-306. doi:10.1037/0022-3514.60.2.300

Clarke-Stewart, A., \& Brentano, C. (2006). Divorce: Causes and consequences. New Haven, CT: Yale University Press.

Cohen, J., Cohen, P., West, S., \& Aiken, L. (2003). Applied multiple regression/correlation analysis for the behavioral sciences (3rd ed.). Hillsdale, NJ: Erlbaum.

Davis, D., Shaver, P., \& Vernon, M. (2003). Physical, emotional, and behavioral reactions to breaking up: The roles of gender, age, emotional involvement, and attachment style. Personality and Social Psychology Bulletin, 29, 871-884. doi:10.1177/0146167203029007006

Dawson, J. F., \& Richter, A. W. (2006). Probing three-way interactions in moderated multiple regression: Development and application of a slope difference test. Journal of Applied Psychology, 91, 917-926. doi:10.1037/0021-9010.91.4.917

Diener, E., Emmons, R., Larsen, R., \& Griffin, S. (1985). The Satisfaction With Life Scale. Journal of Personality Assessment, 49, 71-75. doi:10.1207/s15327752jpa4901_13

Diener, E., Oishi, S., \& Lucas, R. (2009). Subjective well-being: The science of happiness and life satisfaction. In C. Snyder \& S. Lopez (Eds.), Oxford handbook of positive psychology (2nd ed., pp. 187-193). New York, NY: Oxford University Press.

Dörner, J. (2006). A self-concept measure of personality growth: Self-concept Maturity (SCM). Development, validation, and age effects (Dissertation). International University Bremen, Bremen, Germany. 
Everhart, R., Fiese, B., \& Smyth, J. (2008). A cumulative risk model predicting caregiver quality of life in pediatric asthma. Journal of Pediatric Psychology, 33, 809-818. doi:10.1093/jpepsy/jsn028

Fave, G. (2016). Well-being therapy: Treatment manual and clinical applications. New York, NY: Karger.

Frazier, P., \& Cook, S. (1993). Correlates of distress following heterosexual relationship dissolution. Journal of Social and Personal Relationships, 10, 55-67. doi:10.1177/0265407593101004

Gerard, J., \& Buehler, C. (2004). Cumulative environmental risk and youth maladjustment: The role of youth attributes. Child Development, 75, 1832-1849. doi:10.1111/j.1467-8624.2004.00820.x

Gosling, S., Vazire, S., Srivastava, S., \& John, O. (2004). Should we trust web-based studies? A comparative analysis of six preconceptions about internet questionnaires. American Psychologist, 59(2), 93-104. doi:10.1037/0003-066X.59.2.93

Helson, R., \& Srivastava, S. (2001). Three paths of adult development: Conservers, seekers, and achievers. Journal of Personality and Social Psychology, 80, 995-1010. doi:10.1037//0022-3514.80.6.995

Hetherington, M., \& Kelly, J. (2002). For better or for worse: Divorce reconsidered. New York, NY: Norton.

Hewitt, B., \& Turrell, G. (2011). Short-term functional health and well-being after marital separation: Does initiator status make a difference? American Journal of Epidemiology, 173, 1308-1318. doi:10.1093/aje/kwr007

Ivey, A., Ivey, M., Myers, J., \& Sweeney, T. J. (2005). Developmental counseling and therapy: Promoting wellness over the lifespan. Boston, MA: Lahaska Press.

Jones, D., Forehand, R., Brody, G., \& Armistead, L. (2002). Psychosocial adjustment of African American children in singlemother families: A test of three risk models. Journal of Marriage and Family, 64, 105-115. doi:10.1111/j.1741-3737.2002. 00105.x

Kramrei, E., Coit, C., Martin, S., Fogo, W., \& Mahoney, A. (2007). Post-divorce adjustment and social relationships. Journal of Divorce \& Remarriage, 46, 145-166. doi:10.1300/J087v46n03_09

Kraut, R., Olson, J., Banaji, M., Bruckman, A., Cohen, J., \& Couper, M. (2004). Psychological research online: Report of board of scientific affairs' advisory group on the conduct of research on the Internet. American Psychologist, 59, $105-117$. doi:10.1037/0003-066X.59.2.105

Labouvie-Vief, G., \& Medler, M. (2002). Affect optimization and affect complexity: Modes and styles of regulation in adulthood. Psychology and Aging, 17, 571-588. doi:10.1037/0882-7974.17.4.571

Lamela, D. (2013). Divorce and psychological functioning in adults and children (Dissertation). University of Minho, Braga, Portugal.

Lamela, D., Castro, M., \& Figueiredo, B. (2010). Pais por inteiro: Avaliação preliminar da eficácia de uma intervenção em grupo para pais divorciados [preliminary efficacy evaluation of a group intervention program for divorced parents]. Psicologia: Reflexão e Crítica, 23, 334-344. doi:10.1590/S0102-79722010000200016

Lamela, D., \& Figueiredo, B. (2011). Post-divorce representations of marital negotiation during marriage predict parenting alliance in newly divorced parents. Sexual and Relationship Therapy, 26, 182-190. doi:10.1080/14681994.2011.563288

Lamela, D., Figueiredo, B., \& Bastos, A. (2010). Adaptação ao divórcio e relações coparentais: Contributos da teoria da vinculação [adjustment to divorce and co-parental relations: Contributions from the theory of attachment]. Psicologia: Reflexão e Crítica, 23, 562-574. doi:10.1590/S0102-79722010000300017

Lamela, D., Figueiredo, B., \& Bastos, A. (2014). The Portuguese version of the Psychological Adjustment to Separation TestPart A (PAST-A): A study with recently and non-recently divorced adults. Journal of Happiness Studies, 15, 387-406. doi:10.1007/s10902-013-9427-x

Lamela, D., Figueiredo, B., Bastos, A., \& Feinberg, M. (2016). Typologies of post-divorce coparenting and parental wellbeing, parenting quality and children's psychological adjustment. Child Psychiatry \& Human Development, 47, 716728. doi:10.1007/s10578-015-0604-5

Lamela, D., Figueiredo, B., Bastos, A., \& Martins, H. (2014). Psychometric properties of the Portuguese version of the posttraumatic growth inventory short form among divorced adults. European Journal of Psychological Assessment, 30, 3-14. doi:10.1027/1015-5759/a000161

Lucas, R. (2005). Time does not heal all wounds: A longitudinal study of reaction and adaptation to divorce. Psychological Science, 16, 945-950. doi:10.1111/j.1467-9280.2005.01642.x

Luhmann, M., Hofmann, W., Eid, M., \& Lucas, R. (2012). Subjective well-being and adaptation to life events: A meta-analysis. Journal of Personality and Social Psychology, 102, 592-615. doi:10.1037/a0025948

Mancini, A., Bonanno, G., \& Clark, A. (2011). Stepping off the hedonic treadmill: Individual differences in response to major life events. Journal of Individual Differences, 32, 144-152. doi:10.1027/1614-0001/a000047

Masheter, C. (1998). Divorce as selection, stress, and process. Journal of Divorce \& Remarriage, 29, $143-159$.

Middeldorp, C., Cath, D., Beem, A., Willemsen, G., \& Boomsma, D. (2008). Life events, anxious depression and personality: A prospective and genetic study. Psychological Medicine, 38, 1557-1565. doi:10.1017/S0033291708002985

Miller, G., Chen, E., \& Zhou, E. (2007). If it goes up, must it come down? Chronic stress and the hypothalamic-pituitaryadrenocortical axis in humans. Psychological Bulletin, 133, 25-45. doi:10.1037/0033-2909.133.1.25

Mol, S., Arntz, A., Metsemakers, J., Dinant, G., Vilters-van Montfort, P., \& Knottnerus, J. (2005). Symptoms of post-traumatic stress disorder after non-traumatic events: Evidence from an open population study. British Journal of Psychiatry, 186, 494-499. doi:10.1192/bjp.186.6.494 
Mühlig-Versen, A., Bowen, C., \& Staudinger, U. (2012). Personality plasticity in later adulthood: Contextual and personal resources are needed to increase openness to new experiences. Psychology and Aging, 27, 855-866. doi:10.1037/ a0029357

Neto, F. (1993). The satisfaction with life scale: Psychometrics properties in an adolescent sample. Journal of Youth and Adolescence, 22(2), 125-134. doi:10.1007/BF01536648

Novo, R., Duarte-Silva, E., \& Peralta, E. (1997). O bem-estar psicológico em adultos: Estudo das características psicométricas da versão portuguesa das escalas de C. Ryff [psychological well-being in adults: Study of the psychometric properties of the Portuguese version of the C. Ryff scales]. In M. Gonçalves, I. Ribeiro, S. Araújo, C. Machado, L. Almeida, \& L. Simões (Eds.), Avaliação psicológica: Formas e contextos (Vol. V, pp. 313-324). Braga: Associação dos Psicólogos Portugueses.

Orth, U., Robins, R., \& Widaman, K. (2012). Life-span development of self-esteem and its effects on important life outcomes. Journal of Personality and Social Psychology, 102, 1271-1288. doi:10.1037/a0025558

Perrig-Chiello, P., \& Perren, S. (2005). Biographical transitions from a midlife perspective. Journal of Adult Development, 12 (4), 169-181. doi:10.1007/s10804-005-7085-x

Reips, U. (2002). Standards for Internet-based experimenting. Experimental Psychology, 49, 243-256. doi:10.1026//16183169.49.4.243

Rutter, M. (1981). Protective factors in children's responses to stress and disadvantage. In M. Kent \& J. Rolf (Eds.), Prevention of psychopathology (Vol. 3, pp. 49-74). Hanover, NH: University Press.

Ryff, C., \& Keyes, C. (1995). The structure of psychological well-being revisited. Journal of Personality and Social Psychology, 69, 719-727. doi:10.1037/0022-3514.69.4.719

Sakraida, T. (2005). Divorce transition differences of midlife women. Issues in Mental Health Nursing, 26(2), 225-249. doi:10. 1080/01612840590901699

Sameroff, A., Seifer, R., Baldwin, A., \& Baldwin, C. (1993). Stability of intelligence from preschool to adolescence: The influence of social and family risk factors. Child Development, 64, 80-97. doi:10.1111/j.1467-8624.1993.tb02896.x

Sbarra, D., Smith, H., \& Mehl, M. (2012). When leaving your ex, love yourself: Observational ratings of self-compassion predict the course of emotional recovery following marital separation. Psychological Science, 23, 261-269. doi:10. $1177 / 0956797611429466$

Slotter, E., Gardner, W., \& Finkel, E. (2010). Who am I without you? The influence of romantic breakup on the self-concept. Personality and Social Psychology Bulletin, 36, 147-160. doi:10.1177/0146167209352250

Sowislo, J., \& Orth, U. (2013). Does low self-esteem predict depression and anxiety? A meta-analysis of longitudinal studies. Psychological Bulletin, 139, 213-240. doi:10.1037/a0028931

Specht, J., Egloff, B., \& Schmukle, S. (2011). Stability and change of personality across the life course: The impact of age and major life events on mean-level and rank-order stability of the Big Five. Journal of Personality and Social Psychology, 101, 862-882. doi:10.1037/a0024950

Staudinger, U., \& Bowen, C. (2010). Life-span perspectives on positive personality development in adulthood and old age. In R. Lerner, M. Lamb, \& A. Freund (Eds.), The handbook of life-span development (Vol. 2, pp. 254-297). Hoboken, NJ: Wiley.

Staudinger, U., \& Kessler, E. (2009). Adjustment and growth: Two trajectories of positive personality development across adulthood. In C. Smith \& N. DeFrates-Densch (Eds.), Handbook of research on adult learning and development (pp. 241268). New York, NY: Routledge.

Staudinger, U., \& Kunzmann, U. (2005). Positive adult personality development. European Psychologist, 10, 320-329. doi:10.1027/1016-9040.10.4.320

Staudinger, U., Marsiske, M., \& Baltes, P. (1995). Resilience and reserve capacity in later adulthood: Potentials and limits of development across the life span. In D. Cicchetti \& D. Cohen (Eds.), Developmental psychopathology (Vol. 2: Risk, disorder, and adaptation, pp. 801-847). New York, NY: Wiley.

Strouse, J., \& Roehrle, B. (2011). A meta-analysis of intervention outcome studies for adults undergoing separation and divorce. International Journal of Mental Health Promotion, 13, 17-29. doi:10.1080/14623730.2011.9715665

Sutin, A., Costa, P., Wethington, E., \& Eaton, W. (2010). Turning points and lessons learned: Stressful life events and personality trait development across middle adulthood. Psychology and Aging, 25, 524-533. doi:10.1037/a0018751

Sweeper, S., \& Halford, K. (2006). Assessing adult adjustment to relationship separation: The Psychological Adjustment to Separation Test (PAST). Journal of Family Psychology, 20, 632-640. doi:10.1037/0893-3200.20.4.632

Tein, J., Sandler, I., \& Zautra, A. (2000). Stressful life events, psychological distress, coping, and parenting of divorced mothers: A longitudinal study. Journal of Family Psychology, 14, 27-41. doi:10.1037/0893-3200.14.1.27

Uglanova, E., \& Staudinger, U. (2013). Zooming in on life events: Is hedonic adaptation sensitive to the temporal distance from the event? Social Indicators Research, 111, 265-286. doi:10.1007/s11205-012-0004-1

Waller, K., \& MacDonald, T. (2010). Trait self-esteem moderates the effect of initiator status on emotional and cognitive responses to romantic relationship dissolution. Journal of Personality, 78, 1271-1299. doi:10.1111/j.1467-6494.2010. 00650.x

Wallerstein, J. (1986). Women after divorce: Preliminary report from a ten-year follow-up. American Journal of Orthopsychiatry, 56, 65-77. doi:10.1111/j.1939-0025.1986.tb01543.x 
Wang, H., \& Amato, P. (2000). Predictors of divorce adjustment: Stressors, resources, and definitions. Journal of Marriage and Family, 62, 655-668. doi:10.1111/j.1741-3737.2000.00655.x

Weiss, L., Westerhof, G., Bohlmeijer, E., \& Coyne, J. (2016). Can we increase psychological well-being? The effects of interventions on psychological well-being: A meta-analysis of randomized controlled trials. PLoS One, 11, e0158092. doi:10. 1371/journal.pone.0158092

Yárnoz-Yaben, S., \& González, P. (2010). El CAD-S: Un instrumento para la evaluación de la adaptación al divorcioseparación [The CAD-S: An instrument for the assessment of adaptation to divorce-separation]. Psicothema, 22, 157-162. 